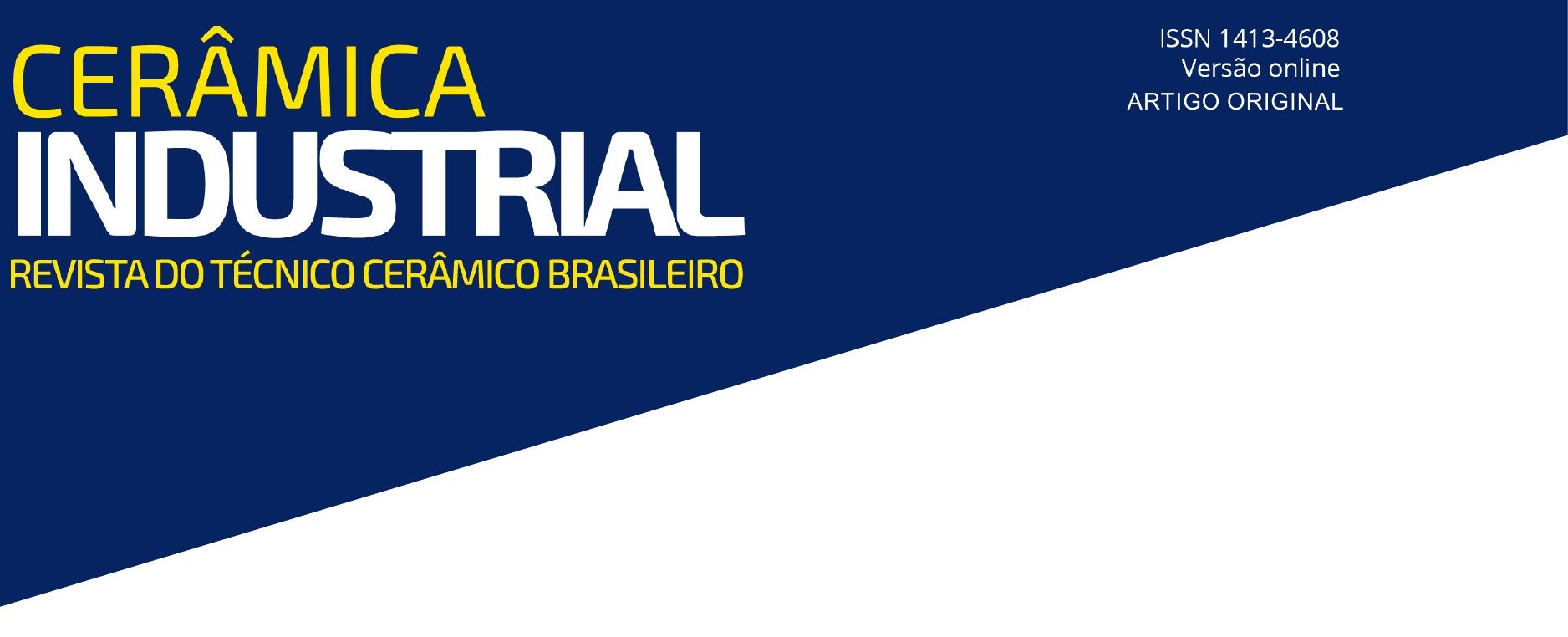

\title{
Efeito da adição de chamote nas propriedades tecnológicas do adoquim
}

\author{
João Paulo dos Santos Silva ${ }^{1 *}$, Roberto Arruda Lima Soares ${ }^{1}$ \\ ${ }^{1}$ Programa de Pós-Graduação em Engenharia de Materiais - Instituto Federal de Educação, Ciência e Tecnologia do Piauí - IFPI \\ *joaopauloec17@gmail.com
}

\begin{abstract}
RESUMO
A utilização de chamote para a produção de adoquim é relevante, pois esse resíduo, ao ser adicionado na massa cerâmica, possibilita a minimização do impacto no meio ambiente. Este estudo tem como objetivo analisar o efeito da adição de chamote nas propriedades tecnológicas do adoquim. As matérias-primas foram coletadas em uma indústria de cerâmica vermelha situada na região de Teresina. Foram realizadas formulações com percentuais de $0 \%, 2,5 \%$, 5\%, $10 \%$ e $20 \%$ de chamote. Os corpos de prova foram preparados por meio de prensagem uniaxial com dimensões de aproximadamente $80 \mathrm{~mm} \times 10 \mathrm{~mm} \times 10 \mathrm{~mm}$ e queimados na temperatura de $1050^{\circ} \mathrm{C}$. As propriedades tecnológicas analisadas foram retração linear de queima, absorção de água, resistência à compressão e resistência à abrasão. $A$ adição de chamote melhorou a propriedade tecnológica de retração linear de queima. Nas demais propriedades, a adição desse resíduo não causou prejuízo significativo. Dessa forma, de acordo com os resultados obtidos, concluiu-se que é viável a adição de chamote na produção do adoquim, pois foram obtidas excelentes propriedades tecnológicas nos corpos de prova.
\end{abstract}

Palavras-chave: Cerâmica vermelha. Adoquim. Chamote. Propriedades tecnológicas.

\section{INTRODUÇÃo}

A matéria-prima básica utilizada na fabricação de produtos de cerâmica vermelha é a argila, mas também podem ser adicionados à argila diversos outros tipos de materiais, como o chamote, por exemplo. Essas adições têm o intuito de melhorar ou, pelo menos, manter em níveis adequados as propriedades tecnológicas dos produtos, assim como possibilitar a redução de custos e a diminuição da degradação gerada no meio ambiente (OLIVEIRA et al., 2016).

Com isso, aliada à adição de resíduos, há a necessidade de as empresas buscarem a fabricação de produtos inovadores, como o adoquim ou piso intertravado cerâmico, como também é conhecido. Esse produto apresenta coloração natural, dispensando o uso de corantes e fácil manuseio, além de apresentar elevada vida útil (FERREIRA et al., 2019).

De acordo com Zaccaron et al. (2014), a fabricação de produtos cerâmicos, em sua maioria, causa problemas ambientais, como a geração de resíduos após a queima. Dessa forma, é necessário o correto gerenciamento dos resíduos cerâmicos pós-queima, que é um procedimento, normalmente, desconhecido pelo ceramista.

$\mathrm{O}$ descarte desses resíduos cerâmicos de forma inadequada causa degradação ambiental e desperdício de matéria-prima. Em meio a isso, tanto os aspectos econômicos como a poluição ambiental gerada são justificativas para pesquisas que busquem a reciclagem e a destinação apropriada desses materiais (SILVA et al., 2017). 
Diante disso, o chamote, que é um resíduo cerâmico submetido a um processo de trituramento, pode ser utilizado no próprio processo produtivo de um produto cerâmico. Essa adição pode melhorar ou manter em padrões adequados, as propriedades tecnológicas desse produto (ZACCARON et al., 2016). Dessa forma, este estudo tem como objetivo analisar o efeito da adição de chamote nas propriedades tecnológicas do adoquim, sendo elas a retração linear de queima, a absorção de água, a resistência à compressão e a resistência à abrasão.

Além disso, verificar a influência da adição de chamote nas propriedades tecnológicas do adoquim apresentase como uma análise inovadora, pois ainda não há estudos que abordam sobre a utilização desse resíduo nas formulações das massas cerâmicas que foram utilizadas. A utilização de variadas formulações permite avaliar de uma forma mais abragente, o efeito que essa adição causa nas propriedades do adoquim.

\section{REFERENCIAL TEÓRICO}

\subsection{Adoquim}

Atualmente, a melhoria da indústria cerâmica pode ser realizada tanto com a implementação de novas tecnologias, como também com a diversificação da produção por meio da fabricação de produtos cerâmicos com elevado valor agregado, como blocos estruturais, telhas e adoquins. Este último é um produto cerâmico, cujo processo de fabricação e posterior utilização ainda está se espalhando no Brasil (CARVALHO et al., 2019).

Segundo Ferreira et al. (2019), o adoquim ou piso intertravado cerâmico é um tipo de pavimento que possui diversos benefícios, como elevada resistência mecânica, variedade de dimensões e relativa facilidade de implantação e de reparação. Com isso, as obras podem ser disponibilizadas ao tráfego logo após a execução.

Em relação à influência da temperatura de queima, o adoquim apresenta melhores propriedades para ser utilizado em passeios, tráfego de veicular leve e tráfego de veículos pesados a partir da temperatura de $1050{ }^{\circ} \mathrm{C}$. Isso ocorre, pois a partir dessa temperatura verificam-se melhorias significativas nas propriedades tecnológicas do produto (SILVA; SANTOS; SOARES, 2020).

No que diz respeito às normas técnicas, o Brasil ainda não possui normas que abordam especificamente sobre o adoquim. Desse modo, enquanto essas normas não forem criadas, é necessário a busca dessa legislação em outros países que já possuem normas que abordam sobre o assunto. Dentre os países que dispõem de normas sobre os pisos intertravados cerâmicos, há os Estados Unidos e a Colômbia, cujas normas foram elaboradas pela American Society for Testing and Materials (ASTM) e pelo Instituto Colombiano de Normas Técnicas y Certificación (ICONTEC), respectivamente.

As normas ASTM C-902 (ASTM, 2015) e ICONTEC NTC 3829 (ICONTEC, 2004a) apresentam os requisitos para a utilização de adoquins em locais que possuem circulação de pedestres e tráfego de veículos leves. Por sua vez, a ASTM C-1272 (ASTM, 2017) e a ICONTEC NTC 5282 (ICONTEC, 2004b) estabelecem padrões para a utilização de adoquins em regiões de tráfego de veículos pesados, calçadas comerciais e aplicações industriais.

\subsection{Adição de chamote em formulações cerâmicas}

Diversas empresas estão buscando reduzir a quantidade de resíduos industriais gerados no processo de produção devido a diversos fatores, como a ausência de área de disposição desses resíduos, a degradação do meio ambiente e a necessidade de resguardar as fontes não renováveis desses recursos naturais. Dessa forma, a reutilização de resíduos pelas empresas é uma alternativa eficiente para a redução desses problemas (COTA et al., 2018).

Diante disso, inúmeras pesquisas estão sendo realizadas para desenvolver diferentes tipos de produtos, como blocos ou telhas, por exemplo, com a adição de um ou mais tipos de resíduos. Com isso, o processo de fabricação de produtos cerâmicos buscou, nas duas últimas décadas, empregar materiais residuais com o objetivo de reduzir as matérias-primas utilizadas no processo de fabricação (AL-FAKIH et al., 2019).

A grande quantidade de resíduos gerados pelas indústrias em um momento de crescentes preocupações ambientais tem incentivado um elevado interesse em reutilizar esses resíduos. A adoção de melhores técnicas de gestão e de resíduos como materiais alternativos a serem usados na fabricação dos produtos resulta na melhoria dos níveis sustentáveis de produção por haver minimização na exploração dos recursos naturais (COLETTI et al., 2018).

A indústria cerâmica apresenta um elevado potencial para a aplicação de resíduos, pois nesse setor existe um elevado volume de produção e um grande consumo de matérias-primas. Além disso, os produtos de cerâmica vermelha dispõem de boa tolerância quanto à mudança nas condições de processamento e às variações na composição das suas matérias-primas. Com isso, é viável a incorporação de quantidades razoáveis de resíduos ou outros materiais na composição de massas cerâmicas (NANDI et al., 2014). 
Diante disso, na fabricação de produtos cerâmicos, além da argila, são acrescentados muitas vezes outros tipos de materiais, como fundentes e resíduos. Dentre os resíduos provenientes das atividades industriais, há o chamote, que são resíduos triturados de peças cerâmicas que foram descartados por possuírem algum tipo de defeito e apresentam, dessa forma, pouca ou nenhuma utilização. A Figura 1 mostra resíduos de blocos cerâmicos que podem ser triturados ou moídos para a produção de chamote (OLIVEIRA et al., 2016).

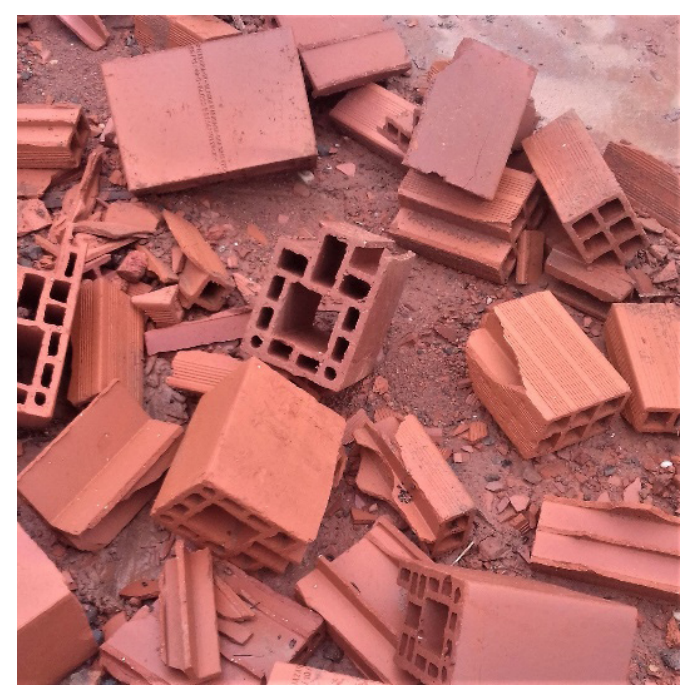

Figura 1: Resíduos de blocos cerâmicos.

Com a incorporação do chamote na massa cerâmica podem ocorrer prováveis ganhos nos produtos cerâmicos, como a otimização do processo de secagem e a diminuição de perdas, com uma possível economia. Além disso, para avaliar diretamente a economicidade dessa adição, pode ser realizada a estimativa do custo de produção do chamote. Dessa forma, o ganho econômico decorrerá da comparação entre o preço da massa argilosa a ser substituída e o custo de beneficiamento desse resíduo (CABRAL JUNIOR; AZEVEDO, 2017).

\section{MATERIAIS E MÉTODOS}

A massa argilosa pronta e os resíduos cerâmicos foram coletados em uma indústria cerâmica situada na região de Teresina, capital do Piauí. Os resíduos cerâmicos coletados na indústria de cerâmica vermelha foram inicialmente colocados em um triturador da marca Trapp, modelo TRF 400, que desagregou e tornou a granulometria desses resíduos menos grosseira, formando, com isso, o chamote. Após a etapa de trituração, as amostras da massa argilosa e do chamote foram submetidas à secagem em estufa da marca Marc Labor à temperatura de $110^{\circ} \mathrm{C}$ durante um período de 24 horas. Em seguida, as matérias-primas foram moídas separadamente em moinho de jarro da marca Solab, modelo SL-34/T, para reduzir e realizar a desagregação das partículas.

As matérias-primas, após a desagregação, foram peneiradas em peneira da ABNT n ${ }^{\circ} 80(0,180 \mathrm{~mm})$. Com as matérias-primas preparadas foram realizadas as etapas de formulação dos corpos de prova, secagem, queima e caracterização. As formulações das massas cerâmicas foram feitas com os teores de $0 \%, 2,5 \%, 5 \%, 10 \%$ e $20 \%$ em peso de chamote, conforme apresentado na Tabela 1 a seguir. Os teores A0, A2,5, A5, A10 e A20 referem-se às formulações utilizadas para a confecção dos corpos de prova.

Tabela 1: Formulações das massas cerâmicas.

\begin{tabular}{ccc}
\multirow{2}{*}{ Formulações das massas cerâmicas } & \multicolumn{2}{c|}{ Concentração em peso (\%) } \\
\cline { 2 - 3 } A0 & Massa argilosa & Chamote \\
A2,5 & 100 & 0 \\
A5 & 97,5 & 2,5 \\
A10 & 95 & 5 \\
A20 & 90 & 10 \\
\end{tabular}


Na preparação dos corpos de prova, inicialmente, as matérias-primas de cada formulação foram colocadas em uma matriz de conformação metálica que apresenta dimensões aproximadamente iguais a $80 \mathrm{~mm}$ x $10 \mathrm{~mm}$ x $10 \mathrm{~mm}$ (comprimento, largura e espessura, respectivamente). Em seguida, foi realizada a moldagem dos corpos de prova de todas as formulações por meio de prensagem uniaxial com intensidade de $35 \mathrm{MPa}$ com o auxílio de uma prensa hidráulica da marca Ribeiro, modelo RP0002. Foram confeccionados 5 corpos de prova para cada formulação.

Em relação à secagem dos corpos de prova, ela foi realizada em estufa da marca Marc Labor a uma temperatura de $110^{\circ} \mathrm{C}$, durante um intervalo de tempo de 24 horas. A queima, por sua vez, ocorreu em forno mufla da marca Quimis, na temperatura de $1050{ }^{\circ} \mathrm{C}$. Após o desligamento do forno, o resfriamento dos corpos de prova ocorreu de forma natural, até alcançarem a temperatura ambiente. A Figura 2 apresenta os corpos de prova queimados na temperatura de $1050{ }^{\circ} \mathrm{C}$.

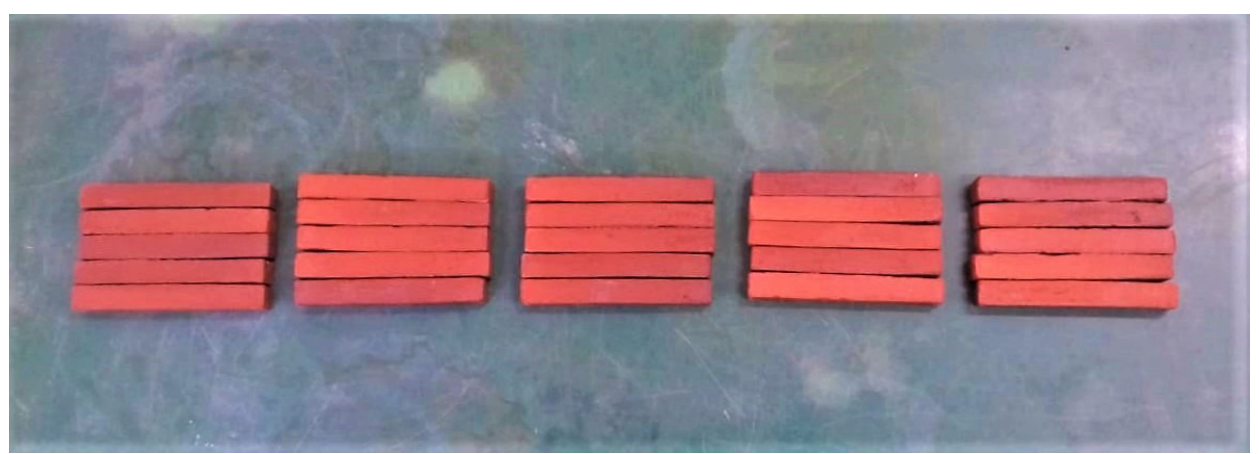

Figura 2: Corpos de prova.

Na caracterização dos corpos de prova queimados, em relação à retração linear de queima (RLQ), os corpos de prova após o processo de queima, foram medidos com o auxílio de um paquímetro digital da marca Zaas, modelo 1,0014, e a partir dos valores do comprimento inicial (Ci) e do comprimento final (Cf), ambos medidos em centímetros (cm), foi realizado o cálculo da RLQ por meio da Equação 1 (ZACCARON et al., 2014).

$$
\operatorname{RLQ}(\%)=\frac{(\mathrm{Ci}-\mathrm{Cf})}{\mathrm{Ci}} \times 100
$$

Com base na norma ASTM C373 (ASTM, 2018b) foi realizado o cálculo da absorção de água (AA). Os corpos de prova, após o resfriamento, foram secos em estufa a uma temperatura de $110^{\circ} \mathrm{C}$ durante $24 \mathrm{~h}$. Em seguida, foram pesados em uma balança digital da marca Ohaus, modelo Adventurer ARC120, medindo-se o peso seco (Ps) em gramas, e, logo após, foram colocados dentro de um recipiente com água destilada durante 24h. A seguir, os corpos de prova foram removidos e pesados novamente, com o intuito de aferir o peso úmido $\mathrm{Pu}$ também em gramas e calcular a quantidade de água que cada corpo de prova absorveu durante a realização do ensaio. A absorção de água foi calculada conforme a Equação 2.

$$
\mathrm{AA}(\%)=\frac{(\mathrm{Pu}-\mathrm{Ps})}{\mathrm{Ps}} \times 100
$$

Segundo a norma ASTM C67 (ASTM, 2018a) foi calculada a resistência à compressão (RC) dos corpos de prova queimados, por meio da relação entre a carga de ruptura do corpo de prova $(\mathrm{F})$ medida em newton $(\mathrm{N}) \mathrm{e}$ a área da seção transversal do corpo de prova (A) medida em $\mathrm{mm}^{2}$. A resistência à compressão foi obtida por meio da Equação 3.

$$
\mathrm{RC}(\mathrm{MPa})=\frac{\mathrm{F}}{\mathrm{A}}
$$

De acordo as normas NTC 3829 (ICONTEC, 2004a) e NTC 5282 (ICONTEC, 2004b), a resistência à abrasão (RA) foi determinada por meio do cálculo do índice de abrasão (IA) dos corpos de prova queimados. Segundo essas normas, a utilização do cálculo do índice de abrasão é um dos métodos que podem ser utilizados para determinar a resistência à abrasão do piso intertravado cerâmico. $\mathrm{O}$ índice de abrasão foi calculado conforme a Equação 4. 


$$
\mathrm{IA}=\frac{0,69 \times \mathrm{AA}}{\mathrm{RC}}
$$

\section{RESULTADOS E DISCUSSÃo}

O chamote ao ser adicionado na massa cerâmica, por ser um material com características inertes, dificulta a retração da peça até alcançar a temperatura em que ele foi obtido, que no caso de blocos e telhas, por exemplo, é em torno de $950{ }^{\circ} \mathrm{C}$. Em temperaturas superiores a essa, esse resíduo apresenta retração próxima à retração da massa argilosa e provoca a redução da retração linear de queima da peça quando se eleva a quantidade adicionada na massa desse resíduo (CASTRO; SOARES; NASCIMENTO, 2012).

No cálculo da retração linear de queima (RLQ) foi utilizada uma média de 5 corpos de prova para cada formulação na temperatura de $1050^{\circ} \mathrm{C}$. Conforme houve aumento no teor de chamote, que é um material não plástico e de granulometria mais grosseira que a massa argilosa, ocorreu uma redução na retração linear de queima, considerando o desvio padrão das amostras. A Tabela 2 e a Figura 3 apresentam os resultados da retração linear de queima dos corpos de prova.

Tabela 2: Retração linear de queima (\%).

\begin{tabular}{cccccc} 
Temperatura & \multicolumn{5}{c}{ Formulação } \\
\cline { 2 - 6 } & $\mathbf{A 0}$ & $\mathbf{A 2 , 5}$ & $\mathbf{A 5}$ & $\mathbf{A 1 0}$ & $\mathbf{A 2 0}$ \\
\hline $1050^{\circ} \mathrm{C}$ & $5,69 \pm 0,17$ & $5,17 \pm 0,13$ & $5,10 \pm 0,05$ & $4,70 \pm 0,06$ & $4,34 \pm 0,18$ \\
\hline
\end{tabular}

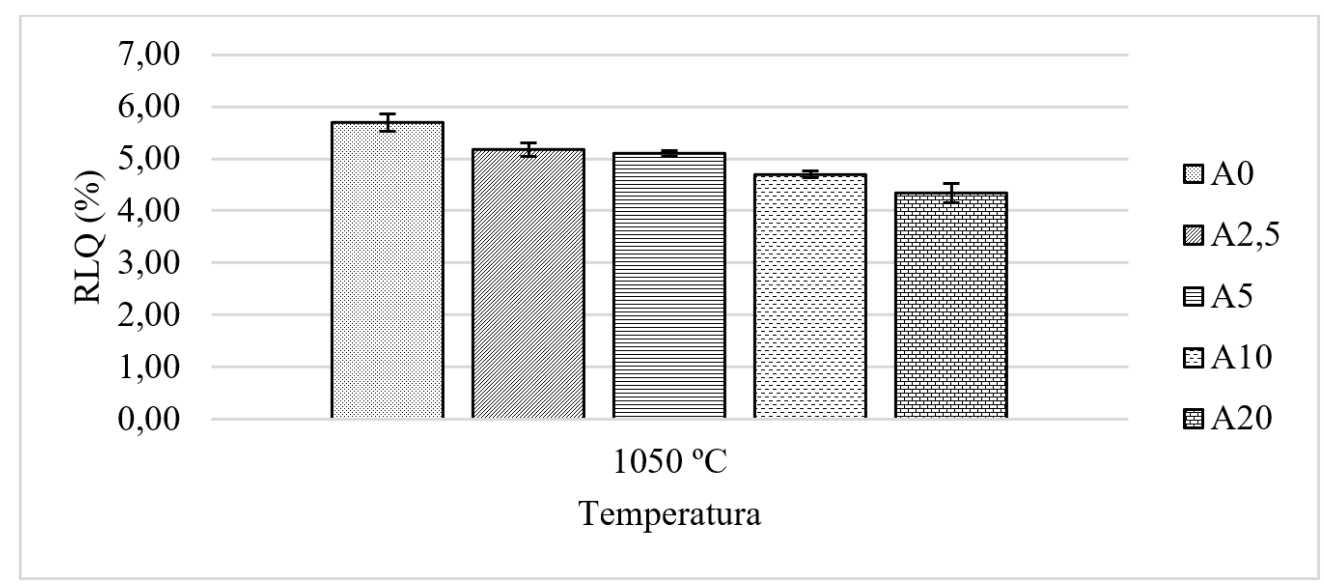

Figura 3: Retração linear de queima dos corpos de prova.

A incorporação de chamote na massa cerâmica influencia diretamente na absorção de água das peças. Com isso, maiores teores de chamote contribuem para elevar a porosidade das peças cerâmicas. Isso ocorre devido à presença de vazios entre as partículas do chamote, que ocasionam o aumento no número de poros das amostras (SOUZA; LIRA; SANTANA, 2017).

Esses poros podem surgir a partir da perda de água durante o processo térmico, podendo também estar relacionados com fenômenos ligados ao empacotamento de partículas. Além disso, esses poros possuem relação com a retração dos grãos do chamote, que ocorre durante o processo de queima (ZACCARON et al., 2016).

A análise de absorção de água (AA) também foi realizada para uma média de 5 corpos de prova para cada formulação. Nesse ensaio, ocorreu um aumento na absorção de água, conforme elevou-se o teor de chamote dos corpos de prova, levando-se em conta o desvio padrão. Isso ocorre, devido ao chamote apresentar uma granulometria mais grosseira em relação à massa argilosa, dificultando, durante a sinterização, o fechamento dos poros existentes na peça. A Tabela 3 e a Figura 4 mostram os resultados obtidos no ensaio de absorção de água dos corpos de prova. 
Tabela 3: Absorção de água (\%).

\begin{tabular}{cccccc}
\multirow{2}{*}{ Temperatura } & \multicolumn{5}{c}{ Formulação } \\
\cline { 2 - 6 } & $\mathbf{A 0}$ & $\mathbf{A 2 , 5}$ & $\mathbf{A 5}$ & $\mathbf{A 1 0}$ & $\mathbf{A 2 0}$ \\
\hline $1050^{\circ} \mathrm{C}$ & $2,31 \pm 0,37$ & $2,53 \pm 0,39$ & $2,92 \pm 0,43$ & $5,51 \pm 0,28$ & $6,13 \pm 0,23$ \\
\hline
\end{tabular}

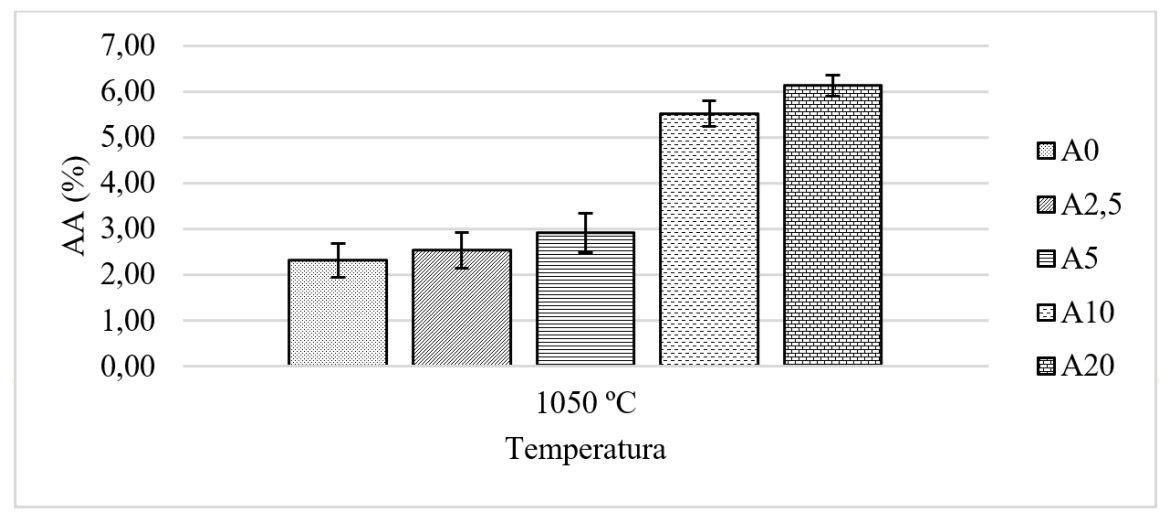

Figura 4: Absorção de água dos corpos de prova.

A adição de chamote em percentuais elevados pode comprometer a qualidade dos produtos cerâmicos, ocasionando, por exemplo, a redução na resistência mecânica desses produtos. Isso pode ocorrer devido ao aumento no número de poros nas amostras ocasionados pela presença desse resíduo (CABRAL JUNIOR; AZEVEDO, 2017).

No ensaio de resistência à compressão $(\mathrm{RC})$ dos corpos de prova, a elevação do teor de chamote ocasionou uma redução na resistência à compressão das amostras, por haver um maior número de poros e uma menor densificação das peças, conforme elevou-se o percentual desse resíduo. Dessa forma, os resultados do ensaio de resistência à compressão das amostras corroboram com os resultados encontrados nos ensaios de retração linear de queima e de absorção de água. A Tabela 4 e a Figura 5 apresentam os resultados encontrados no ensaio de resistência à compressão dos corpos de prova.

Tabela 4: Resistência à compressão (MPa).

\begin{tabular}{cccccc} 
Temperatura & $\mathbf{5}$ Formulação \\
\cline { 2 - 6 } & $\mathbf{A 0}$ & $\mathbf{A 2 , 5}$ & $\mathbf{A 5}$ & $\mathbf{A 1 0}$ & $\mathbf{A 2 0}$ \\
\hline $1050{ }^{\circ} \mathrm{C}$ & $89,17 \pm 4,31$ & $73,75 \pm 7,81$ & $73,20 \pm 7,17$ & $71,68 \pm 7,14$ & $55,71 \pm 9,52$ \\
\hline
\end{tabular}

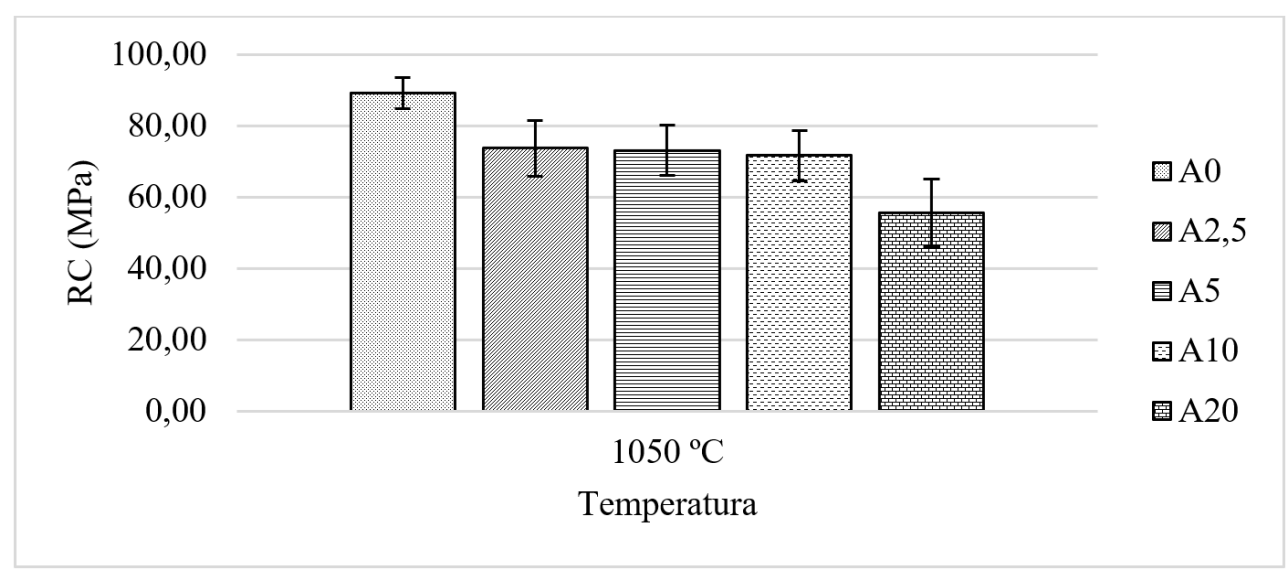

Figura 5: Resistência à compressão dos corpos de prova.

$\mathrm{O}$ aumento do teor de chamote ocasiona redução na resistência à abrasão dos corpos de prova devido ao aumento de porosidade e minimização da resistência mecânica da peça. Com isso, o material removido no processo de abrasão e, consequentemente, o índice de abrasão também se elevam (DIAS et al., 2016). 
A resistência à abrasão (RA) dos corpos de prova, por sua vez, foi determinada por meio do cálculo do índice de abrasão. A resistência à abrasão foi reduzida conforme ocorreu uma elevação no teor de chamote, devido ao maior o índice de abrasão, que ocasionou um maior desgaste superficial nos corpos de prova. Esse maior desgaste foi ocasionado devido ao aumento da absorção de água e à redução da resistência à compressão das amostras. A Tabela 5 e a Figura 6 apresentam os resultados do índice de abrasão dos corpos de prova.

Tabela 5: Índice de abrasão.

\begin{tabular}{cccccc} 
Temperatura & \multicolumn{5}{c}{ Formulação } \\
\cline { 2 - 6 } & $\mathbf{A 0}$ & $\mathbf{A 2 , 5}$ & $\mathbf{A 5}$ & $\mathbf{A 1 0}$ & $\mathbf{A 2 0}$ \\
\hline $1050^{\circ} \mathrm{C}$ & $0,02 \pm 0,01$ & $0,02 \pm 0,01$ & $0,03 \pm 0,01$ & $0,06 \pm 0,01$ & $0,08 \pm 0,02$ \\
\hline
\end{tabular}

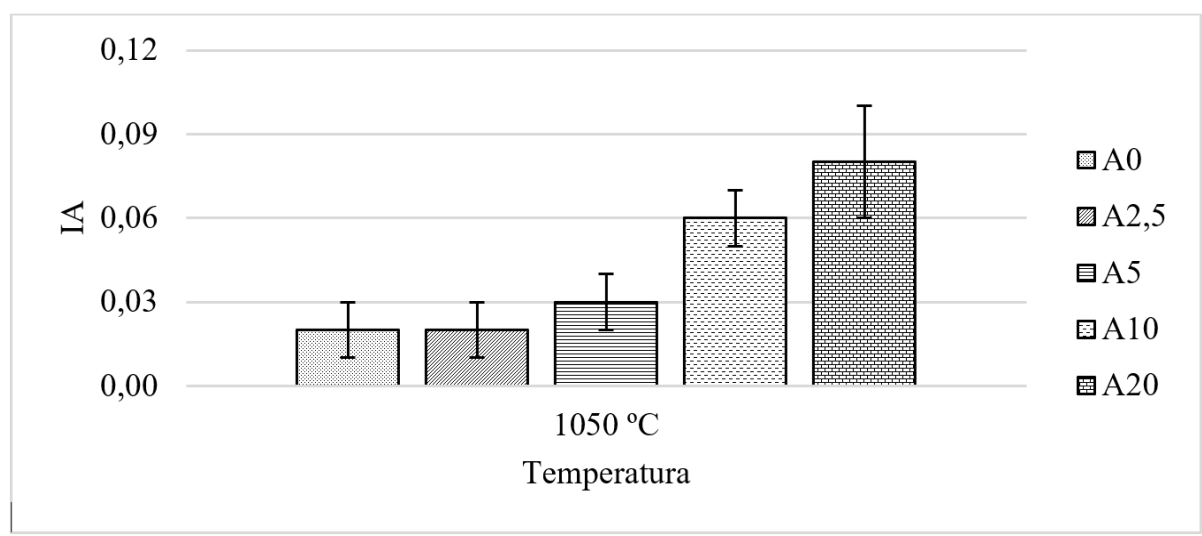

Figura 6: Índice de abrasão dos corpos de prova.

No tocante à norma ASTM C902 (2015), foram consideradas as classificações com maior exigência nessa norma, que são a classe SX que designa que o pavimento está sujeito ao congelamento e o tipo I no qual o piso está sujeito à alta abrasão. No que diz respeito à norma ICONTEC NTC 3829 (2004) também foram consideradas as especificações técnicas relativas ao tipo I. Os valores máximos de absorção de água e do índice de abrasão para essas duas normas são $8 \%$ e 0,11 , respectivamente. Já para a resistência à compressão, o valor mínimo é de 55,2 Mpa. Dessa forma, todas as formulações atenderam a esses requisitos definidos nas normas.

Em relação às normas ASTM C1272 (2017) e ICONTEC NTC 5282 (2004) foram levadas em consideração as especificações técnicas do tipo $\mathrm{F}$, que são relativas a pavimentos flexíveis. Por sua vez, o valor máximo para a absorção de água é de $6 \%$ e para o índice de abrasão é de 0,11 . A resistência à compressão apresenta, segundo essas normas, o valor mínimo de $69 \mathrm{Mpa}$. Com isso, todas as formulações também atenderam a essas especificações estabelecidas nas normas, com exceção da formulação A20, que não atendeu aos valores definidos para a absorção de água e para a resistência à compressão.

\section{CONCLUSÃO}

A adição de chamote nas formulações das massas cerâmicas proporcionou melhoria na propriedade tecnológica de retração linear de queima. Nas demais propriedades, não ocorreu prejuízo relevante com a incorporação desse resíduo na massa cerâmica. Dessa forma, essa adição é benéfica, pois além de melhorar a propriedade de retração linear de queima, se minimiza a quantidade de massa argilosa a ser empregada na fabricação do adoquim.

Em meio a isso, possibilita-se a redução da degradação ambiental das jazidas de extração de argilas, na medida em que decresce a extração dessas matérias-primas. Além disso, a combinação da massa argilosa com o chamote para a fabricação do adoquim proporciona uma excelente aplicação para esse resíduo que, na grande maioria das vezes, não possui uma destinação adequada.

No que se refere à aplicação do adoquim em passeios e em tráfego veicular leve, as propriedades tecnológicas dos corpos de prova foram atendidas em relação às normas técnicas americanas e colombianas. Em relação ao tráfego de veículos pesados, calçadas comerciais e aplicações industriais, os corpos de prova também atenderam às especificações técnicas, exceto a formulação A20, que não atendeu de forma simultânea às especificações para esse tipo de utilização. 
Diante disso, conclui-se que é viável a adição de chamote como um resíduo alternativo na fabricação de adoquim, pois esse resíduo proporciona redução no impacto ao meio ambiente, sem influenciar de forma significativa nas propriedades tecnológicas desse produto. Com isso, a vida útil do produto é mantida, nas suas variadas formas de aplicação.

\section{AGRADECIMENTOS}

Ao Programa de Pós-graduação em Engenharia de Materiais (PPGEM) do Instituto Federal de Educação, Ciência e Tecnologia do Piauí (IFPI) pela oportunidade de realização do Mestrado. À Coordenação de Aperfeiçoamento de Pessoal de Nível Superior (CAPES) pelo apoio financeiro para a realização desta pesquisa. À empresa Telhas Mafrense pelo fornecimento das matérias-primas utilizadas nos ensaios e à Universidade Federal do Piauí (UFPI) por possibilitar a realização do ensaio de resistência à compressão.

\section{REFERÊNCIAS}

AL-FAKIH, A. et al. Incorporation of waste materials in the manufacture of masonry bricks: an update review. Journal of Building Engineering, v. 21, p. 37-54, 2019.

AMERICAN SOCIETY FOR TESTING AND MATERIALS. ASTM C-902: pedestrian and light traffic paving brick. ASTM, 2015.

AMERICAN SOCIETY FOR TESTING AND MATERIALS. ASTM C-1272: heavy vehicular paving brick. ASTM, 2017.

CABRAL JUNIOR, M.; AZEVEDO, P. B. M. Potencial técnico e econômico do aproveitamento de resíduos da indústria de cerâmica vermelha. Cerâmica Industrial, v. 22, n. 3, p. 29-38, mai./jun. 2017.

CARVALHO, J. P. R. G. et al. Development of ceramic paver with ornamental rock waste. Journal of Materials Research and Tecnology, v. 8, n. 1, p. 599-608, jan./mar. 2019.

CASTRO, R. J. S.; SOARES, R. A. L.; NASCIMENTO, R. M. Produção de revestimento cerâmico semi-poroso com adição de chamote de telhas. Matéria, v. 17, n. 4, p. 1166-1175, 2012.

COLETTI, C. et al. Recycling trachyte waste from the quarry to the brick industry: effects on physical and mechanical properties, and durability of new bricks. Construction and Building Materials, v. 166, p. 792-807, 2018.

COTA, T. G. et al. Incorporation of waste from ferromanganese alloy manufacture and soapstone powder in red ceramic production. Applied Clay Science, v. 161, p. 274-281, 2018.

DIAS, L. L. et al. Desenvolvimento de um novo produto cerâmico para pavimentação de passeios e áreas públicas. Ambiente Construído, Porto Alegre, v. 16, n. 4, p. 155-165, out./dez. 2016.

FERREIRA, D. S. et al. Estudo da potencialidade da produção de adoquim com massa cerâmica utilizada em telhas prensadas. Cerâmica Industrial, v. 24, n. 1, p. 40-46, jan./mar. 2019.

INSTITUTO COLOMBIANO DE NORMAS TÉCNICAS Y CERTIFICACIÓN. ICONTEC NTC 3829: adoquín de arcilla para tránsito peatonal y vehicular liviano. Bogotá: ICONTEC, 2004a.

INSTITUTO COLOMBIANO DE NORMAS TÉCNICAS Y CERTIFICACIÓN. ICONTEC NTC 5282: adoquín de arcilla para tráfico vehicular pesado. Bogotá: ICONTEC, 2004b.

NANDI, V. S. et al. Adição de vidro reciclado de lâmpadas na fabricação de cerâmica vermelha. Cerâmica Industrial, v. 19, n. 5, p. 29-32, set./dez. 2014.

OLIVEIRA, Y. L. et al. Estudo da reutilização de resíduos de telha cerâmica (chamote) em formulação de massa para blocos cerâmicos. Cerâmica Industrial, v. 21, n. 2, p. 45-50, mar./abr. 2016.

SILVA, A. L. et al. Avaliação das composições de massas argilosas a partir da incorporação de resíduo da indústria de cerâmica vermelha na obtenção de membranas cerâmicas tubulares. Matéria, v. 22, n. 1, p. 1-8, 2017.

SILVA, J. P. S.; SANTOS, P. J. L. S.; SOARES, R. A. L. Influência da temperatura de queima nas propriedades tecnológicas e microestruturais do piso intertravado cerâmico. Revista de Engenharia e Tecnologia, v. 12, n. 3, p. 247-258, 2020.

SOUZA, M. Y. M.; LIRA, H. L.; SANTANA, L. N. L. Cerâmica porosa - incorporação de chamote em massas contendo ball clay, alumina e talco. Revista Eletrônica de Materiais e Processos, v. 12, n. 3, p. 183-191, 2017.

ZACCARON, A. et al. Incorporação de chamote na massa de cerâmica vermelha como valorização do resíduo. Cerâmica Industrial, v. 19, n. 3, p. 33-39, mai./jun. 2014.

ZACCARON, A. et al. Adição de chamote na massa de cerâmica vermelha como valorização de resíduo na fabricação de blocos de vedação: estudo em escala laboratorial. Revista Engenharia e Construção Civil, Curitiba, v. 3, n. 1, p. 1-16, jan./jun. 2016. 